\title{
La experiencia del debido proceso en la jurisdicción colombiana
}

\section{POR EDUARDO SANTILLÁN PÉREZ $(*)$ Y CARLOS MANUEL ROSALES $(* *)$}

\author{
Sumario. I. Introducción.- II. Concepto.- III. Contenido.- IV. Alcan- \\ ce.- V. Conclusiones.- VI. Bibliografía.
}

Resumen: el debido proceso es una institución que tiene por objeto que las partes tengan acceso a la justicia, por medio de diversas garantías substanciales y de las formalidades legales establecidas. El presente artículo descubrirá esta institución jurisdiccional desde la experiencia de la Corte Constitucional colombiana, en que se desentrañará su concepto, contenido y alcance del debido proceso.

Palabras claves: debido proceso - legalidad - corte constitucional - proceso - jurisprudencia

\section{The due process of law experience in the Colombian judiciary}

Abstract: the due process of law is an institution that has the parts have access to the justice, by means of diverse substantial guarantees and of the legal established formalities. The present article will expose this jurisdictional institution from the experience of the Constitutional Colombian Court, in which there will be discovered his concept, content and scope of the due process.

Keywords: due process - legality - constitutional court - process - jurisprudence

\section{Introducción}

La institución del debido proceso es un mecanismo de defensa contra los abusos o descuido de las autoridades jurisdiccionales. Este dispositivo legal y judicial permite a los sujetos en un proceso, aducir en su protección que algún

$\left({ }^{*}\right)$ Lic. en Derecho, Universidad Nacional Autónoma de México. Prof. Facultad de Derecho, Universidad Nacional Autónoma de México, UNAM. Presidente la Comisión de Justicia del Congreso de la Ciudad de México.

(**) Lic. en Derecho, Universidad Nacional Autónoma de México. Diplomado por la Universidad de Heidelberg. Magister y Doctorado por la Universidad de Chile. Investigador, Centro de Investigación y Docencia Económicas (CIDE), México. 
procedimiento no se llevó conforme a la norma establecida o que no se garantizaron sus derechos fundamentales (Gordillo, 2000, p. 3).

Asimismo, puede servir como recurso para controlar la actividad de los operadores jurisdiccionales ante alguna parcialidad, omisión, abuso o una decisión subjetiva, que afecte su acceso a la justicia o en la impartición de la misma (Hart, 1989, pp. 4 y 64).

La base fundamental del debido proceso es que los actos procedimentales se lleven conforme al principio de legalidad (Hamilton, 2006, p. 22); leyes que fueron expedidas por el poder legislativo y que cuentan con la legitimidad democrática por su fuente soberana (Villotoro, 1978, p. 857).

Sin embargo, empatar al debido proceso con el principio de legalidad es una visión simplificada de lo que comprende esta institución jurídica; porque puede suceder que se demuestre que, si bien se cumplió debidamente con los procedimientos normativos, la sentencia no se aproxima a la justicia (Ruiz, 2012, p. 145).

Por lo que este trabajo expondrá cómo ha sido entendido, razonado y el alcance del debido proceso a partir de las sentencias emitidas por la Corte Constitucional colombiana (Bix, 2004, p. 88).

Este artículo comenzará presentando la forma en que la jurisdicción constitucional colombiana ha definido el debido proceso, los elementos para considerar que hubo un proceso y que se llevó con todas las formalidades, el alcance del mismo, y cuando se reconoce que no hubo un debido proceso. Para finalizar, este trabajo se presentará un conjunto de conclusiones y propuestas sobre la citada figura judicial.

El objetivo de esta monografía es exponer la hermenéutica judicial que se ha creado alrededor del debido proceso en Colombia, y discernir sobre su importancia en la impartición de justicia.

\section{Concepto}

Entender los principios de una cosa o un objeto es primordial para comprender y dimensionar su naturaleza y funciones (Dworkin, 1995, pp. 19-22). Por lo que antes de racionalizar el concepto de debido proceso como institución judicial, se debe conocer que es un proceso (Dworkin, 1995, p. 77 y 78). Ahora, la comprensión del debido proceso implica comprobar que todos los derechos adjetivos y sustantivos fueron considerados y respetados por las autoridades. Lo que hay que reconocer es que cuando un justiciable indica que se debe respetar el debido proceso, es precisamente porque se presume la autoridad no se sujetó al marco 
LA EXPERIENCIA DEL DEBIDO PROCESO EN LA JURISDICCIÓN COLOMBIANA

- Eduardo Santillán Pérez y Carlos Manuel Rosales (PP. 139-170)

https://doi.org/10.24215/25916386e007

normativo (o sea fue "indebido" o "abusivo" el proceder de la autoridad), y, por tanto, ha incumplido su labor.

Es menester mencionar que toda autoridad (pública o privada) puede conculcar o mal aplicar un proceso o procedimiento. Los efectos al solicitar que se revise la actuación de la autoridad o funcionario para calificar su actuación son: la reposición de una actuación o de plano, anular todo el proceso por la gravedad de las violaciones, que no permitirían una correcta y óptima impartición de justicia.

Para comenzar este apartado, se presenta la acepción del concepto "proceso" y que requiere para que se revise y otorgue la calidad de "debido" por parte de la Corte Constitucional colombiana (Sentencia T-158/93):

El proceso es un juicio y es lícito en cuanto implica un acto de justicia. Y como es evidente por la naturaleza procesal se requieren tres condiciones para que un proceso sea debido: Primera, que proceda de una inclinación por la justicia; Segunda, que proceda de la autoridad competente; Tercera, que se profiera de acuerdo con la recta razón de la prudencia, en este caso, que se coteje integralmente toda pretensión, de tal manera que siempre esté presente el derecho de defensa, y que el juez en ningún momento se arrogue prerrogativas que no están regladas por la ley, ni exija, asimismo, requisitos extralegales. Siempre que faltaren estas condiciones, o alguna de ellas, el juicio será vicioso e ilícito.

Es interesante hacer notar los elementos que se describen en la jurisprudencia anterior en que el debido proceso es una solicitud para que haya justicia, o sea es un medio que garantiza la apropiada impartición de justicia. En que se califica, que la autoridad sea la indicada, ya sea por cuestiones de competencia (territorio, grado, materia o cuantía) y que se encuentre habilitada para llevar y resolver ese asunto, caso o negocio. Que la autoridad se conduzca dentro de sus atribuciones (Sorokin, 1982, pp. 471-481) y que cualquier acto fuera de ellas, ya descalifica la calidad del proceso y por tanto demerita la calidad de la administración de justicia, provocando su nulidad de manera parcial o total.

De igual manera, resulta necesario resaltar que si solo hay un debido proceso se puede alcanzar justicia. Por lo que se debe contar con instituciones y normas que permitan a las personas tener acceso a la justicia (Sentencia, T 572/92):

El acceso debe estar enmarcado dentro de unos lineamientos básicos, como lo son el respeto al derecho a un debido proceso y a los principios en él incorporados, como lo son el de la legalidad, la buena fe y la favorabilidad, entre otros. A su vez, surge el deber del Estado, en cabeza de la administración de justicia, una vez se ha tenido acceso a 
ella, conforme a lo dispuesto en la Carta Magna, de que sus decisiones sean públicas y permanentes, con la prevalencia del derecho sustancial, al igual que observar en las actuaciones judiciales los términos procesales con diligencia. De ello surgen entonces principios que se deben cumplir en las actuaciones judiciales, como son el de la eficacia, la publicidad, la permanencia y la celeridad. Se configura en este caso por consiguiente una dilación injustificada del proceso y una indebida y morosa obstrucción para el acceso efectivo a la administración de justicia.

En la referencia anterior se advierten tres elementos indispensables para que haya un debido proceso: legalidad, buena fe y favorabilidad. Cada uno de ellos implica que la autoridad debe actuar conforme lo señala la norma, que sus actuaciones no deben contener un sesgo subjetivo o querer provocar un daño, y que siempre debe conducirse un proceso otorgando el mayor de los beneficios al justiciable; con esto, se puede observar que, si la autoridad se apega lo más posible a la norma y es imparcial, será mejor la impartición de justicia (Bayon, 1996, pp. 143-160).

También indica los principios con que deben operar las autoridades: eficacia, publicidad, permanencia y celeridad (Cabo de la Vega, 1997, p. 258). Sin duda, las instituciones deben trabajar de manera óptima, solo así su resultado será el deseado, por lo que la eficiencia está basada en los resultados que se dan entre lo que indica la norma y la producción positiva que realizan. Los actos de las autoridades no deben ser opacos, para que no generen duda ni sospechas en su labor. Esta transparencia permite que las personas observen como se conduce la autoridad y que no haya resquicios o espacios para que no se dude de su imparcialidad (Squella, 2006, pp. 277-284). La autoridad debe contar con estabilidad laboral, para que pueda impartir libremente su función y no estar acotado, dirigido o manipulado por algo o alguien (interno o externo). Eso le generará permanencia y una posición permanente en su función.

Un tema adicional que se debe considerar es si el tiempo es un factor para que haya un debido proceso. En muchas normas se impone un tiempo de resolución para una causa, pero que puede inaplicarse por el tipo de asunto o por solicitud de las partes (Figueroa, 2012, p. 119). Lo que hay que notar es que esta dilación ya queda como un derecho de las partes, lo que está prohibido es que la autoridad manipule y/o retrase la impartición de justicia, sin un motivo que lo justifique. Pues en caso de retardar la administración de justicia se estaría provocando un daño a la persona e impidiendo que goce de sus derechos a una justicia pronta y expedita. Lo que también conllevaría a revisar si la causa ameritó esos aplazamientos, y, por consiguiente, si la autoridad debe responder por su irresponsabilidad 
LA EXPERIENCIA DEL DEBIDO PROCESO EN LA JURISDICCIÓN COLOMBIANA

- Eduardo Santillán PÉRez y Carlos Manuel Rosales (PP. 139-170)

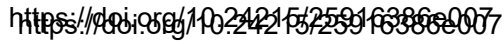

como servidor público, por no resolver en los tiempos que advierte la normatividad respectiva (Sentencia T 572/92):

El funcionario judicial —el juez — debe velar por la aplicación pronta y cumplida de la justicia. Los términos procesales son improrrogables y obligan tanto a las partes como a los jueces. El funcionario que incumpla los términos procesales o que dilate injustificadamente el trámite de una querella, solicitud, investigación o un proceso sin causa motivada, incurrirá en causal de mala conducta. El abuso en la utilización de los recursos y mecanismos procesales, que conducen a la dilación de los trámites jurisdiccionales, contraría este principio. Se debe por tanto fortalecer la institucionalización de la mora como causal de mala conducta, para obligar al Juez a cumplir estrictamente los términos procesales y a darle un curso ágil y célere a las solicitudes que ante la administración judicial presenten los ciudadanos, dentro de la garantía del debido proceso.

Un tema que es importante discernir es en qué ámbitos, espacios e instituciones procede la solicitud para que haya un debido proceso (Sentencia T 496/92):

La figura del debido proceso, es aplicable a toda clase de actuaciones que se realicen en los estrados judiciales e igualmente es válido el debido proceso, para toda actividad de la administración pública en general, sin excepciones de ninguna índole y sin ninguna clase de consideraciones sobre el particular. En el evento sub lite es apenas natural que puede la sociedad actora reclamar que se le desconoce el debido proceso, ya que éste ha de cumplirse en tratándose también de los trámites y procedimientos que se cumplen ante las autoridades administrativas y sin que al efecto tenga que distinguirse si quien adelanta la gestión frente a ellas, sea una persona natural o una persona jurídica. La administración en uno u otro caso, ha de respetar el debido proceso.

En esta interpretación la Corte Constitucional señala como una obligación de toda autoridad pública guardar el debido proceso, lo que conlleva también a un sistema de responsabilidad, en caso de incumplimiento (Redondo, 1999, pp. 149152). Ahora, se puede observar que no se indica que el debido proceso sea exclusivo en su aplicación para el poder judicial, sino para toda autoridad estatal. Lo interesante sería considerar que no solo sean los funcionarios estatales, sino que también las autoridades privadas deben actuar, tutelar y vigilar que el proceso establecido sea cumplido con estándares y elementos mínimos para asegurar que sea "debido", (para pueda ser llevado de manera correcta y oportuna, asegurando los derechos de las partes) (Negretto, 1997, p. 83). 
La fuente primaria para la exigibilidad y justiciabilidad del debido proceso en Colombia, es la Constitución. Asimismo, esta institución se replica en diversas leyes orgánicas para que se garantice el respeto de todos los derechos procesales de las personas (Sentencia T 476/92):

El debido proceso es un derecho constitucional fundamental predicable de toda persona natural como moral cuando con una actuación judicial o administrativa éste ha sido vulnerado o amenazado. No existe vulneración ni amenaza al derecho constitucional fundamental del debido proceso de la persona moral en la actuación administrativa de la Cámara de Comercio y si el apoderado de la sociedad no comparte las decisiones de la Cámara de Comercio, sus alegaciones deben ser dirigidas y resueltas por la autoridad competente.

Esta determinación jurisdiccional revela que tanto personas físicas como morales gozan del mismo derecho para exigir a la autoridad pública o privada, para que se garantice el debido proceso. Lo primero que tendría que revisarse es que el proceso contenga un conjunto de potestades que salvaguarden sus derechos y que no haya espacio para privilegios a costa de sus integrantes. Lo secundario es analizar si se respetaron todas las formalidades contenidos en el cuerpo normativo correspondiente, para analizar si se actuó conforme a la norma y si debe intervenir el poder judicial para que sean restituidos y/o protegidos sus derechos fundamentales (Sentencia T 572/92):

El derecho fundamental al debido proceso es de aplicación inmediata, vincula a todas las autoridades y constituye una garantía de legalidad procesal para proteger la libertad, la seguridad jurídica, la racionalidad y la fundamentación de las resoluciones judiciales. El derecho al debido proceso comprende un conjunto de principios materiales y formales entre los que se encuentran el principio de legalidad, el principio del juez natural o legal, el principio de favorabilidad penal y el principio de presunción de inocencia, todos los cuales responden mejor a la estructura jurídica de verdaderos derechos fundamentales. Una vez se ha particularizado el derecho-garantía a un debido proceso, adquiere el carácter de derecho constitucional fundamental en beneficio de quienes integran la relación procesal. De esa manera quien se sienta amenazado o vulnerado por algún acto u omisión de la autoridad o de los sujetos de la relación procesal, podrá invocar y hacer efectivo los derechos que implícitamente hacen parte del debido proceso.

Lo primordial que se debe examinar para observar si el proceso fue el debido son las formalidades de competencia y si la autoridad esté impedida para resolver 
por alguna causal que le provoque un conflicto de interés, y que podría resolver conforme sus intereses personales (Sentencia T 445/92):

El debido proceso entendido como el conjunto de trámites y formas que rigen la instrucción y resolución de una causa, en cualquiera de las jurisdicciones, es garantía para la debida protección y el reconocimiento de los derechos de las personas. Dentro de este entendido se ha previsto una serie de garantías de independencia y ecuanimidad para quienes tienen como misión la administración de justicia. Consciente el legislador de la naturaleza humana de quienes administran justicia y con el fin de que los jueces sean imparciales, ha establecido una gama de causales que, de existir, pueden restarle objetividad a la intervención del fallador. Para garantizar a los litigantes el adelantamiento imparcial de los procesos y permitirles a los jueces eximirse de intervenir en los juicios en donde no puedan tener absoluta imparcialidad, la ley faculta a aquéllos para que recusen a los jueces y a éstos para que se declaren impedidos.

Es interesante el criterio pretérito, pues adelanta que la imparcialidad es primordial en todo proceso (Trujillo, 2007, p. 310). O sea que el juzgador o ejecutor no debe poseer algún interés en el conflicto; se trata de que se mantenga al margen y que se limite su actuación, si es que tiene un interés directo o indirecto en el conflicto expuesto.

Ninguna autoridad está exenta de estar atento a que todo proceso se lleve de acuerdo con lo establecido en el marco legal (Hernández, 1992, p. 201). Desde el derecho de acceso a la justicia hasta los procesos administrativos que se realizan en el gobierno (Sentencia T 463/92):

El derecho al debido proceso es de obligatoria aplicación a toda clase de actuaciones judiciales y administrativas. El trámite de reconocimientos, entrega de subsidios o devoluciones no está exento de la observancia del debido proceso. Expresión manifiesta de ello es la existencia de diversos recursos legales - reposición y apelación- dentro de la vía gubernativa que permite ser oído y controvertir las decisiones de la administración cuando ellas son adversas a los intereses del solicitante. El margen de apreciación necesaria para el desempeño de las funciones públicas tiene como límite interno la igualdad de trato y de oportunidades. El derecho al debido proceso garantiza la igualdad ante la ley al exigir de la autoridad un mismo tratamiento frente a todas las personas, sin favoritismos ni discriminaciones.

Esta jurisprudencia otorga la misma importancia y calidad a todo justiciable y a todo proceso, en el que se garantice la respectiva igualdad formal ante el Estado, y 
de trato por los órganos públicos, sin preferencia en las personas y en sus asuntos (Pérez, 2016, pp. 16-19).

Entonces, si se empieza a vislumbrar este asunto, se puede afirmar que hay un debido proceso en sentido material cuando la autoridad ha actuado conforme a las normas preestablecidas (que son su ámbito de ejercicio), y que cualquier acto o conducta fuera de sus facultades es ilegal, abusivo y por tanto inválido. Esto es determinado en la doctrina como principio de legalidad (Sentencia T 623/17):

La sujeción de sus autoridades al derecho, y en particular, la garantía que tal sometimiento representa para los derechos de las personas, tiene dos consecuencias fundamentales. La primera de ellas, que el principio de legalidad resulta exigible a todas las autoridades estatales. Particularmente a las autoridades judiciales, a quienes corresponde garantizar la efectividad de los derechos de las personas. La segunda consecuencia consiste en que cuando la actuación de una autoridad judicial resulta contraria a la legalidad, y con ello se desconocen los derechos fundamentales de las personas, estos pueden ser objeto de protección mediante la acción de tutela. En efecto, como no puede haber autoridades estatales cuya actividad no esté sometida a la legalidad, y como de tal sujeción depende la vigencia de los derechos y libertades constitucionales fundamentales, la actividad de los jueces ordinarios está sujeta al control de tutela que ejerce el juez constitucional.

Asimismo, la Corte interpretó al principio de legalidad como:

El principio constitucional de la legalidad tiene una doble condición de un lado es el principio rector del ejercicio del poder y del otro, es el principio rector del derecho sancionador. Como principio rector del ejercicio del poder se entiende que no existe facultad, función o acto que puedan desarrollar los servidores públicos que no esté prescrito, definido o establecido en forma expresa, clara y precisa en la ley. Este principio exige que todos los funcionarios del Estado actúen siempre sujetándose al ordenamiento jurídico que establece la Constitución y lo desarrollan las demás reglas jurídicas (...). Su posición central en la configuración del Estado de derecho como principio rector del ejercicio del poder y como principio rector del uso de las facultades tanto para legislar - definir lo permitido y lo prohibido- como para establecer las sanciones y las condiciones de su imposición, hacen del principio de legalidad una institución jurídica compleja conforme a la variedad de asuntos que adquieren relevancia jurídica y a la multiplicidad de formas de control que genera la institucionalidad (Sentencia, T 710/01). 
Por lo que la inobservancia de la norma o sea la ilegalidad (por acción u omisión) es el acto que origina un indebido proceso, y que ha producido un perjuicio a la persona. Pero si un proceso no fue llevado con todas sus formalidades, es decir, si contiene un error que no afecta el fondo del proceso, se podría considerar excepcionar ese procedimiento y continuar con el mismo, por ejemplo, no anotar el número de identificación de la persona que recibió una notificación. Este tema invita a considerar y reflexionar sobre la gravedad de la informalidad, y meditar si debe reponer el procedimiento o continuar con el proceso de la causa (Sentencia T 248/93):

La inobservancia de las reglas que rigen para cada proceso, no sólo cuando se adelanta uno diferente al que legalmente corresponde, sino cuando dentro del pertinente no se siguen las secuencias que le son propias por ley, es lo que constituye una violación y un desconocimiento al principio del debido proceso. La accionante sí conoció de la existencia del proceso por conducta concluyente, ya que quedó vinculado al proceso, participando dentro del mismo, y concretamente, en la diligencia de inspección ocular, por lo que ha podido hacer uso de los medios judiciales para defender sus intereses.

Uno de los objetivos que se promueve con el debido proceso es garantizar todos los derechos de los justiciables y el control de la autoridad (Orozco, 1982, pp. 830832). Esto deriva en que sea el estado de Derecho el que impere como mecanismo de protección y de estricta aplicación de la norma, sin concesiones ni privilegios (Escuin, 2004, pp. 25-26). Así, lo reconoce la Corte Constitucional colombiana al definir al estado de derecho:

Por Estado de Derecho se debe entender el sistema de principios y reglas procesales según los cuales se crea y perfecciona el ordenamiento jurídico, se limita y controla el poder estatal y se protegen y realizan los derechos del individuo. Surge entonces el derecho de defensa de la persona frente al Estado, que se rige por un proceso (Sentencia $\mathrm{T}$ 049/93).

Se debe analizar cuál es la consecuencia de aplicar la norma que garantice seguridad jurídica y justicia a las personas. Por lo que la aplicación del principio de legalidad si bien es para frenar los actos de las autoridades, indirectamente se protege de abusos a la población, para que, en caso de una supuesta arbitrariedad, los jueces constitucionales escuchen su petición y resuelva conforme a derecho (Sentencia T 584/92):

En un Estado social de derecho, toda función pública debe estar sujeta a una regulación jurídica preexistente que garantice al individuo 
receptor de la acción su derecho de defensa. Y para el ejercicio de este derecho no basta con poner en conocimiento de dicha persona la decisión final, sino que es necesario brindarle la posibilidad de que ella muestre al ente decisor competente su verdad, sus alegatos, en fin, su visión de los acontecimientos.

Para concluir este apartado es preciso empezar a visualizar el siguiente subtema: el contenido y las formas para que se considere que no hubo un debido proceso y la autoridad dictamine que se debe hacer para reparar ese daño. Esto materializa la eficacia del Estado, efectividad de la norma y legitima su valor ante la sociedad (Sentencia T 383/00):

La transgresión que pueda ocurrir de aquellas normas mínimas que la Constitución o la ley establecen para las actuaciones procesales, como formas propias de cada juicio, atenta contra el debido proceso y desconoce la garantía de los derechos e intereses de las personas que intervienen en el mismo. De esta manera, logra ignorar el fin esencial del Estado social de derecho que pretende brindar a todas las personas la efectividad de los principios y derechos constitucionalmente consagrados, con el fin de alcanzar la convivencia pacífica ciudadana y la vigencia de un orden justo. Sin embargo, la violación del derecho al debido proceso no sólo puede predicarse del incumplimiento de una determinada regla procesal; también ocurre por virtud de la ineficacia de la misma para alcanzar el propósito para el que fue concebida. Así, en la medida en que el derecho sustancial prevalece sobre las formas procesales, como mandato que irradia todo el ordenamiento jurídico $\mathrm{y}$, muy especialmente, las actuaciones destinadas a cumplir con la actividad judicial, es que las formas procesales que la rijan deben propender al cumplimiento de los propósitos de protección y realización del derecho material de las personas y a la verdadera garantía de acceso a la administración de justicia. Con ello no se quiere significar que las reglas de procedimiento, legalmente establecidas, puedan resultar inobservadas sin discriminación por los funcionarios encargados de conducir el respectivo proceso; por el contrario, éstas deben aplicarse con estricto rigor en la medida de su eficacia para realizar los derechos e intereses de las personas, so pena de convertir en ilegítimos los actos efectuados sin su reconocimiento.

Por tanto, la consecuencia de un debido proceso es asegurar que las personas no tengan incertidumbre de sus derechos, brindando seguridad jurídica de la comunidad. El efecto es también provocar la sana convivencia entre el poder público y las personas que exigen que sean contemplados, respetados, vigilados y tutelados sus prerrogativas y, por otro lado, que también haya un mecanismo de 
LA EXPERIENCIA DEL DEBIDO PROCESO EN LA JURISDICCIÓN COLOMBIANA

- Eduardo Santillán Pérez y Carlos Manuel Rosales (PP. 139-170)

https://doi.org/10.24215/25916386e007

efectividad para que se controle y regularice los actos del poder, y que haya una identificación entre la norma y las leyes; pero, sobre todo, que el derecho recupere su función social.

A continuación, se presentarán los elementos que integran el debido proceso, desde la visión de la jurisdicción constitucional en Colombia.

\section{Contenido}

Al hacer la interpretación constitucional de esta figura jurisdiccional, la Corte consideró el papel y los elementos del debido proceso:

El artículo 29 de la Constitución dispone, de una parte, que toda actuación se desarrolle con sujeción al procedimiento legalmente preestablecido en la materia. Y, de otra, constituye una limitación a los poderes del Estado, habida cuenta de que corresponde al legislador establecer previamente la infracción, las sanciones a que se hacen acreedores quienes incurran en estas y la definición de las autoridades públicas o administrativas competentes para realizar la investigación y, consecuentemente, imponer la sanción. La jurisprudencia constitucional ha sostenido de manera reiterada que el debido proceso es el conjunto de garantías previstas en el ordenamiento jurídico orientadas a la protección del individuo incurso en una conducta judicial o administrativamente sancionable, precisando que son elementos integradores del debido proceso los siguientes: 'a) el derecho a la jurisdicción y el acceso a la justicia; b) el derecho al juez natural; c) el derecho a la defensa; d) el derecho a un proceso público, desarrollado dentro de un tiempo razonable; e) el derecho a la independencia del juez y f) el derecho a la independencia e imparcialidad del juez o funcionario' (Sentencia C 412-15).

En otra sentencia, adicionó varios subprincipios que constituyen el debido proceso jurisdiccional:

El debido proceso posee una estructura compleja contiene que contiene diversos principios, normas y reglas, y que a continuación se transcribe: 'Hacen parte de las garantías del debido proceso: (I) El derecho a la jurisdicción, que a su vez conlleva los derechos al libre e igualitario acceso a los jueces y autoridades administrativas, a obtener decisiones motivadas, a impugnar las decisiones ante autoridades de jerarquía superior, y al cumplimiento de lo decidido en el fallo; (II) el derecho al juez natural, identificado como el funcionario con capacidad o aptitud legal para ejercer jurisdicción en determinado proceso o actuación, de 
acuerdo con la naturaleza de los hechos, la calidad de las personas y la división del trabajo establecida por la Constitución y la ley; (III) El derecho a la defensa, entendido como el empleo de todos los medios legítimos y adecuados para ser oído y obtener una decisión favorable. De este derecho hacen parte, el derecho al tiempo y a los medios adecuados para la preparación de la defensa; los derechos a la asistencia de un abogado cuando sea necesario, a la igualdad ante la ley procesal, a la buena fe y a la lealtad de todas las demás personas que intervienen en el proceso; (IV) el derecho a un proceso público, desarrollado dentro de un tiempo razonable, lo cual exige que el proceso o la actuación no se vea sometido a dilaciones injustificadas o inexplicables; (V) el derecho a la independencia del juez, que solo es efectivo cuando los servidores públicos a los cuales confía la Constitución la tarea de administrar justicia, ejercen funciones separadas de aquellas atribuidas al ejecutivo y al legislativo y (VI) el derecho a la independencia e imparcialidad del juez o funcionario, quienes siempre deberán decidir con fundamento en los hechos, conforme a los imperativos del orden jurídico, sin designios anticipados ni prevenciones, presiones o influencias ilícitas (Sentencia C 341/14).

El fundamento teleológico del debido proceso es la seguridad jurídica y una eficaz administración de justicia. Con esto se reconoce que cuando el justiciable no tiene un juicio justo, es porque hubo un indebido proceso y que se rompió con el equilibrio procesal, generando una desigualdad en el proceso que debe ser reparada (Sentencia T 140/93):

El fundamento del debido proceso, lo encontramos en los principios de la justicia y la seguridad jurídica; éstos exigen que se empleen medios idóneos para dar estabilidad y seguridad a las partes dentro del proceso, en el que se ventilan sus pretensiones con objetividad, esto es, imparcialmente, con la apreciación del todo probatorio, y jamás limitándose a escrutar tan sólo un sector. En tal caso la decisión sería unilateral, y lo unilateral excluye la alteridad, la cual, es requisito sine qua non de todo acto verdadero de justicia, la cual es por naturaleza una virtus sociales - referida siempre al otro-. La causa final del debido proceso no es otra que garantizar el equilibrio armónico de las partes entre sí, bajo la dirección de un tercero imparcial que estará dispuesto a dar el derecho a quien le corresponda, en virtud de lo probado, es decir, de lo evidenciado por las partes bajo parámetros de legitimidad y oportunidad.

En esta definición se descubren los objetivos del debido proceso: el reequilibrio procesal y la defensa de los derechos de las personas. Pero surge otro tema, 
en el momento en que se realizó el indebido proceso, la responsabilidad de la autoridad ante la ilegalidad de su actuación. Por lo que se consideró que es parte de un debido proceso que no solo se subsane el procedimiento o se anule el proceso, sino que sea sancionada la autoridad responsable y lógicamente, al demostrarse el daño a la persona sea indemnizada por esa vulneración a sus derechos.

Pero surge una vacilación, si un acto es consentido o no es impugnado en el tiempo procesal oportuno, ise podría solicitar la nulidad del procedimiento y su inmediata reposición? Y aquí nace un tema importante, el valor de la cosa juzgada y hasta qué momento se podría decir que hubo un debido, justo, honesto, público, imparcial y correcto proceso.

Pero aún no se ha señalado los elementos o principios que componen el debido proceso, por lo que es menester exponerlos y circunscribir su relación con la administración de justicia (Sentencia T 572/92):

El derecho fundamental al debido proceso es de aplicación inmediata, vincula a todas las autoridades y constituye una garantía de legalidad procesal para proteger la libertad, la seguridad jurídica, la racionalidad y la fundamentación de las resoluciones judiciales. El derecho al debido proceso comprende un conjunto de principios materiales y formales entre los que se encuentran el principio de legalidad, el principio del juez natural o legal, el principio de favorabilidad penal y el principio de presunción de inocencia, todos los cuales responden mejor a la estructura jurídica de verdaderos derechos fundamentales. Una vez se ha particularizado el derecho-garantía a un debido proceso, adquiere el carácter de derecho constitucional fundamental en beneficio de quienes integran la relación procesal. De esa manera quien se sienta amenazado o vulnerado por algún acto u omisión de la autoridad o de los sujetos de la relación procesal, podrá invocar y hacer efectivo los derechos que implícitamente hacen parte del debido proceso.

Por lo que se señala que el debido proceso es para toda autoridad, que tiene por objeto proteger diversos derechos y que se administra bajo el principio de legalidad, el principio del juez natural o legal, el principio de favorabilidad penal y el principio de presunción de inocencia, entre otros (dependiendo de cada competencia y autoridad). En el que el justiciable tendrá que demostrar sus afirmaciones, basado en las pruebas que pueda presentar y se pueda observar la afectación en el proceso, y, por tanto, el detrimento de su esfera jurídica.

Como ya se mencionó, la legalidad es uno de los principios rectores del debido proceso. Pero en el análisis de esta institución al caso concreto, se debe visualizar si la autoridad actuó fundando y motivando sus determinaciones: 
Una de las dimensiones del debido proceso es la motivación del acto. Todo acto debe ser motivado con expresión de las razones justificativas, como desarrollo del principio de legalidad, para determinar si este se ajusta a la ley o si corresponde a los fines señalados en la misma (Sentencia T 187/93).

En otras palabras, hay que analizar todo el marco normativo que rodea las facultades de la autoridad, para comprender la naturaleza de sus actos y resolver si ha actuado apegado a la norma, y calificar si ese acto fue arbitrario, discrecional, abusivo y por tanto ilegal.

Por lo antes expuesto se observa que el debido proceso está conformado por diversos principios, reglas y derechos que sustentan la calificación de lo "debido" en un proceso, y comprobar si se han cumplido con cada uno de ellos. Pero al mismo, tiempo se debe reflexionar en el proceso como una estructura teleológica, un mecanismo de defensa, de eficacia de la ley y de funcionabilidad social, por lo que hace esta institución judicial un elemento clave para contener el poder de la autoridad y garantizar todos los derechos adjetivos y sustantivos de las personas (Sentencia C 475/97):

El debido proceso es un derecho de estructura compleja que se compone de un conjunto de reglas y principios que, articulados, garantizan que la acción punitiva del Estado no resulte arbitraria. Algunas de las reglas constitucionales que configuran este derecho son de aplicación inmediata y anulan cualquier norma que las limite o restrinja. Así, por ejemplo, el derecho a la legalidad del delito y de la pena no admite restricción ninguna, como tampoco el principio de la no reformatio in pejus, o el principio de favorabilidad (C.P. artículo 29). No obstante, otros de los elementos integrantes del debido proceso tienen la estructura lógica de estándares o reglas que deben ser aplicadas prima facie, y admiten ponderaciones o limitaciones útiles, necesarias y proporcionadas para asegurar la vigencia de otro derecho fundamental o de un interés constitucional de igual entidad. En particular, el derecho de defensa es uno de aquellos derechos que plantea parámetros de actuación que deben ser regulados por el legislador garantizando su máxima aplicación, pero cuidándose de afectar otros derechos o bienes constitucionalmente valiosos que se encuentran en juego en el juicio penal o administrativo.

Cuando un proceso sea observado como indebido, se debe considerar los derechos de la otra parte que no fue beneficiada. Esto que implica que las prerrogativas de la contraparte pueden ser afectadas en esta decisión judicial, al reponer o anular los derechos de la persona afectada por una nefasta actuación de la autoridad. 
La defensa que se haya ejercido, el tiempo invertido y los recursos del Estado serán desechados ante la declaración de que no hubo un debido proceso, por lo que la seguridad jurídica del adversario y de cosa juzgada también quedan supeditadas al debido proceso.

A continuación, se presenta la jurisprudencia que crea un parámetro, para comprobar si se ha llevado el debido proceso por parte de la autoridad (Sentencia C 496-15):

La necesidad de racionalizar el ejercicio del poder público y privado hace necesario un proceso que garantice (I) la definición de los elementos básicos que estructuran cualquier relación jurídica, señalando tanto los supuestos relevantes para reconocer una conducta como jurídicamente significativa, como los efectos (consecuencias o sanciones) que se siguen de su incumplimiento; (II) la identificación de la autoridad que es el tercero imparcial competente para adoptar las decisiones relativas a los desacuerdos que surjan en la relación jurídica; (III) la existencia de medios jurídicos (acciones o recursos) que se puedan emplear en los casos en los que quienes hacen parte de una determinada relación jurídica estiman necesario la intervención de un tercero (la autoridad competente) para resolver las posibles diferencias que se originan en dicha relación jurídica; (IV) el conocimiento por parte de todos los interesados, tanto de los elementos que estructuran la relación jurídica que se establece y sus efectos concretos, como de los remedios jurídicos de los que gozan las partes para proteger sus intereses, y, finalmente; (V) el efectivo ejercicio de las herramientas jurídicas con las que el interesado puede adelantar su defensa ante las autoridades o terceros. Estos elementos, tanto procedimentales como sustanciales, estructuran la garantía del debido proceso.

El debido proceso actúa como un mecanismo de defensa al controlar el poder de la autoridad (Valadés, 2000, p. 65) pero también produce transparencia y rendición de cuentas de cómo ejerció sus potestades. Esto faculta que la autoridad sea cuestionada por su actuación o por las prerrogativas que la normatividad le concede (Sentencia T 1232/00):

En cualquier clase de proceso que adelante la administración en desarrollo de su actividad y en la cual involucre a un particular, deberá de tener en cuenta los pasos y procedimientos preestablecidos en cada tipo de proceso, y que estos se deben agotar a fin de poder llegar a la toma de una decisión, sea esta judicial o administrativa. Es, por ello, que para que el derecho sustancial que se encuentre involucrado en la decisión que toma la autoridad, se vea protegido, debe estar permanente acompañado y respaldado por un procedimiento y unas for- 
https://doi.org/10.24215/25916386e007

malidades preexistentes que permitan su vigencia, pues dicho trámite agiliza y da transparencia a la actuación de la autoridad permitiendo la búsqueda del orden justo.

En cuanto al papel del debido proceso en la impartición de justicia, se presenta la siguiente jurisprudencia que define su función en un Estado social de derecho (Sentencia T 073/97):

La Constitución consagró el derecho fundamental al debido proceso, entendido éste como el conjunto de garantías que procuran la protección del individuo incurso en una actuación judicial o administrativa, para que durante su trámite se respeten las formalidades propias de cada juicio. La norma constitucional lo consagra para todo tipo de actuaciones, de manera que las situaciones de controversia que se presenten en cualquier proceso estén previamente reguladas en el ordenamiento jurídico, el cual debe señalar las pautas que procuren el respeto de los derechos y obligaciones de las partes procesales para que ninguna actuación de las autoridades tenga origen en su propio arbitrio, sino que obedezca a los procedimientos descritos en la ley y los reglamentos. El debido proceso propende por una debida administración de justicia, la cual, a su vez, constituye una de las más importantes garantías para el amparo de los intereses legítimos de la comunidad y contribuye a la permanencia del Estado social de derecho.

Para continuar se presenta el alcance que debe tener el debido proceso. Se expondrán las consecuencias que se producen al ejecutarse un indebido uso del poder de la autoridad, la vulneración del orden jurídico, la restauración de los derechos fundamentales de las personas y la consecuente responsabilidad de la autoridad.

\section{Alcance}

Ya se ha visto el concepto y el contenido del debido proceso, pero queda pendiente saber cuáles son los efectos cuando se ha reconocido que no se llevó el proceso de la forma indicada por la ley y, sobre todo, qué hacer ante la violación de los derechos sustantivos y procesales de las personas, para que sea reparado el acto y se genere certidumbre y seguridad jurídica en el Estado; por lo que el debido proceso se posiciona como un instrumento primordial para que la autoridad pueda impartir justicia (Sentencia T 516/92):

El carácter fundamental del derecho al debido proceso proviene de su estrecho vínculo con el principio de legalidad al que deben ajustarse no sólo las autoridades judiciales sino también, en adelante, las admi- 
LA EXPERIENCIA DEL DEBIDO PROCESO EN LA JURISDICCIÓN COLOMBIANA

- Eduardo Santillán Pérez y Carlos Manuel Rosales (PP. 139-170)

nistrativas, en la definición de los derechos de los individuos. Es pues una defensa de los procedimientos, en especial de la posibilidad de ser oído y vencido en juicio, según la fórmula clásica, o lo que es lo mismo, de la posibilidad de ejercer el derecho de defensa. El derecho al debido proceso comprende no solo la observancia de los pasos que la ley impone a los procesos judiciales y a los procesos y trámites administrativos, sino, también el respeto a las formalidades propias de cada juicio, que se encuentran, en general, contenidas en los principios que los inspiran, el tipo de intereses en litigio, las calidades de los jueces y funcionarios encargados de resolver.

Esta jurisprudencia contiene un elemento importante, la calidad que deben gozar las autoridades responsables del debido proceso. Estas personas deben tener una calidad profesional, un servicio de vocación pública y social y también estar sujetas a un sistema de responsabilidades, en caso de incumplir con las obligaciones propias de su función. Desde que se le otorga un poder a la autoridad son responsables del uso del mismo, por lo que en su selección se debe procurar que posean una calidad para que no abusen de sus facultades (Sentencia T 1341/01):

Dentro del campo de las actuaciones administrativas 'el debido proceso es exigente en materia de legalidad, ya que no solamente pretende que el servidor público cumpla las funciones asignadas, sino además que lo haga en la forma como determina el ordenamiento jurídico'. Efectivamente, las actuaciones de la Administración son esencialmente regladas y están sujetas a dicho principio de legalidad. El poder de actuación y decisión con que ella cuenta no puede utilizarse sin que exista una expresa atribución competencial; de no ser así, se atentaría contra el interés general, los fines esenciales del Estado y el respeto a los derechos y las libertades públicas de los ciudadanos vinculados con una decisión no ajustada a derecho.

Sin duda la forma de contener el poder de la autoridad está en la calidad de la autoridad y en un plano material y que sea anulado todo acto que no provenga de sus funciones o que lo use para un interés personal. La legalidad como instrumento del debido proceso permite que el mismo poder sea limitado, y consecuentemente, se sancione ese abuso.

Es importante comprender que el debido proceso es una estructura compleja (Tribe, 1991, p. 67) esto significa, que se debe observar que la naturaleza de que cada proceso es único, y que está construido por diversos derechos y de diferentes etapas, en que cada una de ellas tiene sus propias características hacia un objetivo, garantizar todos los derechos y, por tanto, se pueda resolver conforme a la norma, respetando los derechos sustantivos del justiciable (Sentencia T 945/01): 
El derecho al debido proceso hace referencia a un conjunto complejo de circunstancias (por ejemplo, la definición del status de las personas, o la consagración de actos, etapas, oportunidades e intercambios), señaladas por la Constitución y la ley que 'protegen al ciudadano sometido a cualquier proceso', asegurándole a lo largo del mismo la posibilidad de defender sus intereses mediante el señalamiento expreso de los requisitos y obligaciones que debe cumplir y de los recursos con los que cuenta para impugnar las decisiones de la autoridad. Pero también la existencia de un principio de esta naturaleza refiere la necesidad de dar cumplimiento a una secuencia de actos, relacionados entre sí de manera directa o indirecta, que persiguen un objetivo adicional: la racionalización del ejercicio del poder de tal manera que se reconozca en la ley, y no en la voluntad, en la fuerza, o en la arbitrariedad, la forma de resolución de las contenciones de derecho. Así, como tantas veces lo ha dicho la Corte, 'las actuaciones que adelanten los funcionarios judiciales o las autoridades administrativas, deben observar y respetar en todo momento las normas que regulen los procedimientos a seguir, con el fin de preservar las garantías - derechos y obligaciones- de quienes se encuentran incursos en una relación jurídica, en todos aquellos casos en que la actuación conduzca a la creación, modificación o extinción de un derecho o a la imposición de una sanción'

Se desprende de la pretérita jurisprudencia varios elementos a considerar y razonar. La racionalización del proceso indica una sujeción de etapas o pasos concatenados, coherentes, lógicos y armonizados que están contenidos en uno o varios cuerpos normativos. Y que cualquier acto fuera de la ley es ilegal, lo que significa que la autoridad violó la legalidad, produciendo una lesión al proceso (Zagrebelsky, 1997, p. 23). Pero también puede ser que se haya hecho un acto legal, pero que atente contra los derechos de las personas y que se analice si ese abuso vulneró el proceso. Por ejemplo, en el caso de los procesos abreviados o de supresión de etapas procesales, se debe de tener en consideración los derechos de las personas más allá de la economía procesal, observando no violar los derechos de las personas, por lo que cualquier mecanismo para reducir algún procedimiento debe estar de conformidad absoluta de las partes, y conocer plenamente los derechos a los que están renunciando.

Un tema que también se produce con el debido proceso es anular la desventaja que se creó a partir de un indebido proceso. El efecto al reparar un procedimiento o anular un proceso es que la arbitrariedad cometida por la autoridad sea nulificada, y que la persona sea protegida en su esfera jurídica (Sentencia T 945/99):

El debido proceso está consagrado en la Carta Política como un derecho de rango fundamental que se aplica en todas las actuaciones judi- 
LA EXPERIENCIA DEL DEBIDO PROCESO EN LA JURISDICCIÓN COLOMBIANA

- Eduardo Santillán Pérez y Carlos Manuel Rosales (PP. 139-170)

https://doi.org/10.24215/25916386e007

ciales y administrativas. Según la jurisprudencia constitucional, el proceso es debido cuando se ajusta a las previsiones legales, se acomoda a las formas propias de cada juicio y garantiza el derecho de defensa de los asociados. A través de la garantía del debido proceso, el Estado logra impedir que las controversias jurídicas se tramiten según el capricho de los funcionarios encargados de resolverlas, pero también busca que la administración de justicia se imparta según criterios homogéneos que garanticen la seguridad jurídica y el principio de igualdad. Adicionalmente, por la sola circunstancia de ser un derecho fundamental, el debido proceso en cuanto garantía ciudadana puede ser reclamado judicialmente por vía de acción de tutela, pues el carácter sumario y prevalente de este procedimiento, hacen de él un mecanismo idóneo para evitar que los agentes encargados de la administración de justicia resuelvan los conflictos sometidos a su consideración por fuera de la juridicidad, es decir, acudiendo a las vías de hecho.

Hasta ahora se ha fijado al principio de legalidad como uno de los pilares del debido proceso, pero hay que considerar su fuente, el poder legislativo. Si en la elaboración de las leyes hay un error, defecto u omisión en un proceso o procedimiento, se debe considerar que los ejecutantes e intérpretes de la ley deben de obedecer la norma como les fue otorgada, para que la usen para impartir justicia. Pero qué tanto podría alejarse o no aplicar una norma que les ha sido impuesta, y no tener un problema de responsabilidad. Pero la autoridad podría no aplicar una norma violatoria de derechos, porque los legisladores lo consideraron para que haya una justicia más eficaz; por ejemplo, en varios países, los casos de cuantía menor no contemplan el derecho a recurrir (Sentencia T 795/98):

El artículo 29 de la Carta Política consagra el derecho fundamental al debido proceso, como el conjunto de garantías que procuran la protección del individuo incurso en una actuación judicial o administrativa, para que durante su trámite se respeten las formalidades propias de cada juicio y se logre la aplicación correcta de la justicia. En consecuencia, para que la protección a este derecho sea efectiva, es necesario que cada uno de las etapas procesales estén previamente definidas por el legislador, pues, de lo contrario, la función jurisdiccional quedaría sujeta a la voluntad y arbitrio de quienes tienen la función de solucionar los conflictos de los asociados y de resolver sobre la interdependencia de sus derechos. La previa definición legal de los procedimientos que constituyen el debido proceso, ha sido denominada por la Constitución Política, como 'formas propias de cada juicio', y se constituye en consecuencia, en la garantía de referencia con que cuentan las personas para determinar en qué momentos la conducta de los jueces o de la administración se convierte en ilegítima, por descono- 
cerse lo dispuesto en las normas legales, constituyéndose en una vía de hecho. Resulta contrario al ordenamiento jurídico el que un funcionario encargado de adelantar procedimientos judiciales o administrativos que resuelvan sobre derechos subjetivos, proceda conforme su voluntad, desconociendo las pautas que la ley le ha señalado para el ejercicio de su función, pues en tal caso, su actuación subjetiva y caprichosa se convierte en una vía de hecho, por la vulneración al debido proceso legal.

Se debe presuponer que todo proceso expedido por los legisladores contendrá todos los elementos mínimos para que se pueda administrar justicia. En el que la norma, contenga y considere los aspectos sustantivos y adjetivos para que un proceso sea razonable, justo e imparcial. Por ejemplo, en el caso de renuncia de derechos en un proceso, se puede considerar que se da un caso, no se podría alegar posteriormente, que el proceso no fue el debido por esa decisión. Los acuerdos judiciales están contemplados en la norma para dar celeridad y generar economía procesal al proceso o procedimiento, observando que el acuerdo está conforme a las reglas, que fue aprobado por la autoridad y que no vulneró los derechos de las personas.

Pero ¿quién debe comprobar que no se ha llevado el cumplimiento del debido proceso? Ante esta situación de violación de derechos, lógicamente tiene que ser un superior el que revise el caso, pero no solo en cuanto al derecho que se presume ha sido conculcado, sino que debe revisarse todo el proceso para comprobar que no haya otras violaciones normativas (Sentencia T 166/00):

El debido proceso está consagrado en la Constitución política dentro del rango de los derechos fundamentales. Siguiendo la profusa jurisprudencia de la Corte Constitucional sobre la materia, puede afirmarse que parte de su contenido esencial reside en la premisa según la cual las decisiones judiciales y administrativas deben estar cimentadas tanto en los principios constitucionales como en las previsiones legales y reglamentarias, de tal modo que la resolución de los conflictos particulares o la definición de los derechos individuales, no queden al arbitrio del juzgador sino que, por el contrario, sean producto de la aplicación directa de la ley. Gracias al alcance que constitucionalmente se le ha reconocido a este derecho, el Estado puede garantizar que la Administración de justicia se imparta según criterios homogéneos que promuevan la seguridad jurídica y mantengan vigentes los principios de igualdad y legalidad. Pero adicionalmente, la Corte Constitucional ha dicho que esta garantía - la del debido proceso-, por razón de su jerarquía, puede hacerse efectiva a través de la acción de tutela, lo cual significa que cualquier persona que se considere afectada por una de- 
LA EXPERIENCIA DEL DEBIDO PROCESO EN LA JURISDICCIÓN COLOMBIANA

- Eduardo Santillán Pérez y Carlos Manuel Rosales (PP. 139-170)

https://doi.org/10.24215/25916386e007

cisión judicial o administrativa, proferida por fuera del ordenamiento legal, pueda acudir a este mecanismo preferente para obtener inmediata protección.

Es interesante reconocer que los procesos no solo se dan en el espacio administrativo y judicial, sino que también en el esfera de los particulares, por ejemplo: un arbitraje, una votación en un conjunto de condóminos, el ingreso a una universidad, una huelga, la forma como se lleva una asamblea en una asociación, una conciliación, una certificación, una licitación, entre tantos actos, espacios y profesiones que requieren de un conjunto de procedimientos y procesos, para que se puedan llevarse a efecto los mismos. Por lo que la Corte Constitucional colombiana estimó que el alcance del debido proceso se debía colocar y observar fuera de la materia pública, y, por tanto, también se debía vigilar que los derechos de las personas se protegieran por medio del debido proceso en el ámbito privado (Sentencia T 546/00):

El derecho al debido proceso considerado de manera abstracta constituye una aplicación del principio de legalidad dentro de un proceso judicial o administrativo. Tal definición, aún sin necesidad de que se determinen el contenido y los alcances del derecho, tiene una repercusión fundamental: garantizarles a las personas que la actividad de las autoridades estatales va a seguir un conjunto de reglas procesales establecidas de antemano. Este derecho, así formulado, brinda a los individuos seguridad frente a la actividad estatal, y garantiza que dichas reglas se apliquen por igual a todos, como consecuencia del carácter general y abstracto de la ley procesal. De tal modo da aplicación a tres principios jurídicos fundamentales: la seguridad jurídica, la legalidad de los procedimientos y la igualdad de las personas frente a la ley. Como regla general, el derecho al debido proceso tiene cabida, únicamente, en procedimientos que sigan las autoridades administrativas o judiciales, y sólo excepcionalmente en las actuaciones de los particulares.

Es importante esta jurisprudencia porque reconoce que también en el ámbito privado se debe proteger y vigilar los derechos sustantivos y adjetivos para que el proceso sea conforme a la normativa, y se considere que fue el debido, o en su caso reconocer que aquel proceso no garantiza que haya igualdad, imparcialidad, transparencia, recursos a las partes, publicidad, inviolabilidad de derechos fundamentales, entre otros; y excitar a que los particulares dispongan de reglas, principios y derechos para establecer un proceso justo (Sentencia T 116/04):

El debido proceso, como derecho fundamental no se agota en el principio de legalidad. Este derecho, en clave constitucional, apunta a que 
https://doi.org/10.24215/25916386e007

el procedimiento aplicable sea compatible con la Constitución y a que, en el desarrollo del procedimiento, sea administrativo o judicial, se respeten las garantías que permiten calificar dicho procedimiento de justo (en particular, juez natural, carácter público del procedimiento, derecho de defensa, derecho a controvertir las pruebas y doble instancia en materia penal). De lo anterior, se desprende que no toda violación del procedimiento legal implica violación del derecho fundamental al debido proceso.

En una nueva interpretación del alcance del debido proceso, se consideró y relativizó la gravedad de la violación en el procedimiento, esto significa, que si bien pudo haber una transgresión por la forma en cómo se realizó un acto intraprocesal (sin violar un derecho fundamental), no menos cierto, es que ese acto no repercutió en la substanciación del proceso; por lo que si bien se reconoce una violación adjetiva, no tiene la calidad ni peso para influir en el resultado final del proceso.

Sin embargo, definir el debido proceso es muy complejo porque depende de la naturaleza de cada área, o sea, es específico por su materia y ámbito, en cuanto a su forma y fondo. Lo que el juzgador(a) comprueba en cada proceso es si el mismo proceso protege los derechos fundamentales y si sus procedimientos permiten alcanzar una determinación justa, correcta e imparcial, y que no haya ninguna arbitrariedad (Sentencia T 116/04):

Una cosa es la efectividad de la garantía constitucional, que no depende de la ley en cuanto no proviene de ésta, y otra muy distinta, la verificación acerca del contenido del debido proceso en relación con cada caso, que siempre tendrá por factor de comparación lo dispuesto en la ley correspondiente. Eso implica que, si bien el derecho constitucional al debido proceso no precisa de un estatuto legal que lo haga reclamable de manera inmediata y plena, siempre habrá de verse, para deducir si tal derecho ha sido respetado o es objeto de violación, cuáles son las reglas procesales aplicables en el evento específico, es decir, las generales y abstractas, vigentes con anterioridad e integrantes de la ley prevista para cada proceso.

Por lo que se descubre, que existen elementos mínimos para considerar una teoría de un núcleo básico en el debido proceso (Sobrevilla, 2005, pp. 98-113) mismos que deben ser observados por el impartidor de justicia para verificar no solo el proceso en ese caso; sino que se analiza de forma neutra, por medio de un modelo mínimo de derechos que debe contener, y para que haya una actuación eficiente de la autoridad (Herrendorf, 1994, pp. 97-109). 
Las formas para hacer exigible la garantía de un debido proceso son dos: la constitucionalidad del fallo y el recurso legal que se presenta ante el superior del que emitió un indebido proceso (Sentencia C 252/01):

La casación no puede confundirse con la acción de revisión, aunque ambas sean medios de impugnación extraordinarios, pues en la primera se cuestiona la juridicidad del fallo, es decir, la estricta observancia de la ley y la Constitución, y en la segunda se cuestiona la decisión judicial porque la realidad allí declarada no corresponde a la verdad objetiva o real, debido al surgimiento de hechos nuevos que no se conocieron durante el trámite del proceso y que, necesariamente, inciden en ella.

En el análisis de la misma jurisprudencia, también se estableció qué se debía de hacer en caso de que hubiera un conflicto entre normas. Siempre será de observancia obligatoria la supremacía constitucional (Sentencia C 252/01):

Los problemas prácticos de la administración de justicia no pueden solucionarse con el sacrificio de derechos fundamentales de las personas. En caso de presentarse conflicto entre un derecho fundamental e inalienable de la persona humana, y la conveniencia de adecuar una institución a objetivos prácticos alcanzables de otro modo, sin duda ha de prevalecer la garantía del primero. Para ambos objetivos prácticos debe haber remedios adecuados que no resulten violatorios de los derechos fundamentales y del ordenamiento superior.

Este criterio establece la preponderancia de la Constitución, sobre cualquier norma legal, acuerdo judicial, convenio privado o institución procesal particular, y en caso de conflicto, prevalezca la Constitución (Nino, 1996, pp. 1-5).

Dos temas de relevancia son: en qué tiempo se considera que hay una vulneración en el proceso por no impartir justicia, y en qué instante se vuelve un acto consentido, no reclamar por la vía legal o constitucional, que supone violó sus derechos (Sentencia T 538/94):

El sindicado es sujeto procesal y no víctima procesal. Las consecuencias del error judicial que enmienda y corrige el superior, no pueden gravitar negativamente en la parte procesal hasta el punto de que ésta pierda la oportunidad de utilizar un recurso de defensa por haberlo presentado dentro del término que le indicó el juzgado de la causa con base en una interpretación prima facie razonable, esto es, por haber conformado su conducta procesal a los autos y demás actos procedentes de dicho despacho judicial. La administración de justicia, a través de las diferentes instancias, debe corregir sus propios errores, pero no 
a costa del sacrificio del legítimo derecho de defensa de los sindicados y menos escarmentando la buena fe que ellos razonadamente hayan puesto en los actos de las autoridades. Los dictados de la buena fe se ignoran al obrar con tan máxima severidad y dar lugar a iniquidad manifiesta. En definitiva, para corregir el error judicial —falencia interna del servicio de administración de justicia - no era necesario sacrificar de manera tan palmaria el derecho de defensa del sindicado y considerar falta suya el haber confiado razonadamente en la autoridad pública.

Es menester presentar un ejemplo de un acto consentido y su validación dentro del proceso (Sentencia C 541/92):

La norma acusada propende por la vigencia efectiva del principio de lealtad procesal y por el de la realización de la Justicia; así, cuando dentro de la etapa investigativa cualquiera de los sujetos procesales se percate de la existencia de una nulidad, debe de inmediato ponerla en conocimiento del Fiscal que adelante el caso. Además la norma acusada no contraría el Debido Proceso por cuanto los sujetos procesales cuentan con oportunidades suficientes para invocar las nulidades de los actos procesales originadas en la etapa de investigación y el juez está dotado de facultades oficiosas para declararlas; además, la 'convalidación' transitoria de las no invocadas dentro de las oportunidades señaladas no se opone al principio del adelantamiento de un proceso libre de cualquier vicio de evidente raigambre constitucional, todo lo contrario, pretende que se llegue a la etapa de juzgamiento y se adelante ésta con la mayor garantía posible.

Un tema derivado de un indebido proceso es la responsabilidad del sujeto que realizó el acto. Por lo que se debe cuestionar si un debido proceso debe contar con un sistema de sanciones y de responsabilidad objetiva del estado, por una mala administración de justicia (Sentencia T 218/96):

Todos y cada uno de los jueces y magistrados son el poder judicial y todos ejercen a plenitud la jurisdicción, según una distribución funcional reservada a la ley, lo que implica que cada uno de ellos sea el titular de ese poder y no la organización en su conjunto. El juez puede hacer un uso indebido de la potestad jurisdiccional que tiene, e incurrir en actuaciones no ajustadas a derecho, arbitrarias, que vulneren derechos fundamentales del individuo como el derecho a la libertad y al debido proceso; cuando así ocurra, quien se vea afectado por esas actuaciones o decisiones, puede defender sus derechos fundamentales por vía de tutela, o si es el caso, si en aras de imponer una sanción de tipo correccional el juez ordena arbitraria e ilegalmente su deten- 
LA EXPERIENCIA DEL DEBIDO PROCESO EN LA JURISDICCIÓN COLOMBIANA

- Eduardo Santillán PÉrez y Carlos Manuel Rosales (PP. 139-170)

https://doi.org/10.24215/25916386e007

ción, puede también acudir a la acción de hábeas corpus, prevista en la Carta política y en la ley.

Queda un tema que analizar: se debe indemnizar a la persona que se le vulneró un derecho y que por tanto no gozó de un debido proceso. ¿Qué tipo de arbitrariedades deberían ser indemnizadas y cuáles deberían ser de índole administrativas o disciplinarias, para el juzgador, la autoridad o el funcionario por su irresponsabilidad o arbitrariedad? Son apartados que deben resolver las autoridades administrativas, como el Consejo de la Judicatura, el Consejo de Estado y del Tribunal Contencioso administrativo.

Para sellar este trabajo se presenta la jurisprudencia que determina la relación del debido proceso y la impartición de justicia:

El debido proceso compendia la garantía de que todos los demás derechos reconocidos en la Carta serán rigurosamente respetados por el juez al resolver asuntos sometidos a su competencia, como única forma de asegurar la materialización de la justicia, meta última y razón de ser del ordenamiento positivo (Sentencia C 252/01).

Es primordial señalar que la Corte Constitucional Colombiana ha señalado las diferencias del debido proceso jurisdiccional y el administrativo, y por tanto también sus causas y sanciones no son las mismas:

Las garantías procesales en el campo administrativo sancionatorio no son iguales a las del ámbito judicial, toda vez que se enmarcan dentro de rasgos y etapas diversas. El debido proceso en las actuaciones administrativas opera en tres momentos específicos: (I) en la formación de la decisión administrativa (acto administrativo), (II) en la notificación o publicación de esa decisión administrativa, y (III) en la impugnación de la decisión (recursos) (Sentencia, C 412/15).

Un apartado que merece debida atención es el debido proceso en las relaciones particulares, pues ellos no están sujetos a la legalidad; sin embargo, el proceso los rige y debe contener ciertos parámetros para que no haya abusos ni arbitrariedades. La Corte Constitucional Colombiana se refirió sobre estas situaciones:

La exigibilidad de la garantía del debido proceso respecto de los particulares encuentra sustento, asimismo, tanto en la eficacia del texto constitucional frente a los vínculos que se circunscriben bajo su vigencia, como también en la interrelación e interdependencia que guardan los derechos entre sí, en tanto componentes propios de su carácter universalista e indivisible (...). El respeto del debido proceso, en el marco de la imposición de sanciones, implica la observancia de: (I) el princi- 
pio de legalidad, (II) la debida motivación de la decisión que atribuye efectos jurídicos a la conducta de quien es sujeto de sanción, (III) la publicidad e imparcialidad en las etapas del trámite, (IV) la competencia estatutaria del organismo decisorio, y (V) el derecho a la defensa y contradicción en el curso del procedimiento. Sentencia T 623/17.

A continuación, se despliega un conjunto de conclusiones que señalan los aportes más importantes de la institución del debido proceso que ha elaborado la Corte Constitucional Colombiana.

\section{Conclusiones}

El Estado democrático constitucional de derecho es la institución de donde dimanan las entidades públicas, que tienen por objeto tutelar, garantizar y vigilar los derechos y las libertades de todas las personas.

A partir del reconocimiento y positivación de los derechos fundamentales de cada sociedad, se establece un conjunto de normas sustantivas y adjetivas, para que la población acuda a las instituciones públicas, para su protección y se validen las prerrogativas constitucionales.

El debido proceso es una institución jurisdiccional, que se origina y produce de la actuación del juzgador, o dicho en términos del juez Stewart (EE. UU.), el debido proceso es la correcta administración de las leyes.

El debido proceso es una figura adjetiva y sustantiva, que se integra con un conjunto de subprincipios y valores que permiten que las partes en un juicio, obtengan una resolución justa. Por lo que se podría deducir, que cuando un proceso se apega más a las normas legales, más cerca se estará de obtener justicia, y viceversa, si un juez no se conduce conforme a la normatividad, su sentencia será, negligente, ilegal, corrupta, ilegítima, e injusta.

Como se anotó anteriormente, el debido proceso se integra de diversos principios, dependiendo el tema judicial del que se trate. Por ejemplo, se puede encontrar un proceso (protocolo) para la custodia de la prueba, que va desde su recolección y resguardo, hasta su desahogo. Y que las violaciones en el manejo de las mismas, podrían hacerlas invalidas, de manera parcial o total, dependiendo de la gravedad de la violación que se haya cometido. Pero sería justo, qué un mal manejo de la prueba viole los derechos de la contraparte o que no permita accionar eficazmente la autoridad.

Como se mencionó, el debido proceso es un tema integral y multifactorial, que se origina de los distintos derechos del justiciable, pero también cuida la forma en 
LA EXPERIENCIA DEL DEBIDO PROCESO EN LA JURISDICCIÓN COLOMBIANA

- Eduardo Santillán Pérez y Carlos Manuel Rosales (PP. 139-170)

cómo el juzgador tuteló cada uno de esos derechos: por lo que, al hablar del debido proceso, es menester exponer que parte o elemento del proceso fue incumplido o violado, para pensar en anular o reparar ese proceso. Por lo que el debido proceso es muy relativo, y cada caso es una historia judicial, que se persigue de la forma prescrita con anterioridad. Se intenta y procura que no se genere un menoscabo en el proceso o en algún procedimiento, y en caso de que se detecte alguna violación, se analice si esta afectó la forma o el fondo del proceso.

Este trabajo confirma y valida la importancia fundamental y primordial del debido proceso como eje rector jurisdiccional. En el entendido de que, en cada negocio judicial, son las disposiciones normativas las que determinan los derechos de las partes, las que señalan el rol del juzgador y las exigencias del contenido de la sentencia. Y que cualquier desvío daría para solicitar la invalidación, por no seguirse el proceso tal y como advierten las leyes vigentes.

La primera visión para considerar que hubo un debido proceso es analizar si ese proceso contiene los elementos procedimentales y sustanciales necesarios para considerar que permite su objetivo.

El debido proceso es una institución jurídica que sirve al justiciable como garantía para brindar acceso a la justicia, conforme al desarrollo de la normatividad. Asimismo, tiene diversas maneras de cómo entenderlo y visualizarse: teleológico, instrumental, garantista, institucional, funcional, entre varios que se expusieron.

Así, pues, uno de los ejes fundamentales del debido proceso es la legalidad. Este principio es trascendental para el desarrollo y sustento del proceso. La legalidad no solo genera una conducta de la autoridad, sino que también permite observar y comprobar que se han llevado todas las formalidades, en el que la forma que establece el código adjetivo, pero sin que se violenten bajo ninguna circunstancia los derechos fundamentales de la persona.

Otro principio fundamental del debido proceso es el de imparcialidad, que garantiza una conducta independiente, objetiva y profesional del juzgador o autoridad (Guarnieri, 1999, p. 16). Pues, en caso de que se favoreciera a alguna de las partes, se quebrantaría el principio de igualdad procesal, lo que provocaría una jurisdicción parcial y/o un indebido ejercicio como servidor público.

El debido proceso es un lente que permite a las partes procesales verificar si el proceso contiene un conjunto de derechos mínimos que garanticen un servicio, y, por otro lado, la observancia de que el proceso se llevó conforme a la normatividad adjetiva y sustantiva. Y en su caso, solicitar lo que le convenga a la persona desde la reposición procedimental hasta la anulación del mismo proceso. Por lo 
https://doi.org/10.24215/25916386e007https://doi.org/10.24215/25916386e007 que hay que entender que el debido proceso depende de cada caso y de lo que se desea obtener al referirlo y solicitarlo.

Por ello, el debido proceso es una responsabilidad de la autoridad, que tiene la obligación de dirigir de manera diligente cada proceso. Esto traerá como consecuencia certidumbre y seguridad jurídica al justiciable (Comanduci, 1999, p. 98); produciendo como consecuencia la legitimación de la autoridad ante la sociedad, y del proceso como el instrumento para obtener justicia o un servicio, y, por tanto, se produce eficacia judicial. En el que la sociedad verá reflejada sus aspiraciones y derechos con las leyes establecidas y la justicia impartida.

En caso de que no se haya llevado un debido proceso se pueden vislumbrar varias consecuencias (que ya se mencionó, como la reposición procedimental o anulación procesal), pero hay otras repercusiones que solo enunciaré (por no ser tema aparte del principal) como la reparación del daño por medio de la responsabilidad objetiva del Estado y la responsabilidad de la autoridad (y más, si fue cometida por un servidor público).

Deseo comentar que existe un área de excepción al principio de debido proceso. Pues a partir de la libertad con la que cuentan los contratantes, en que podrían convenir no considerar ciertos derechos (como la jurisdicción), y por otra parte, la prerrogativa judicial de no seguir un procedimiento en la manera que indica la norma (por ejemplo, la entrevista en casa de menores, y no un interrogatorio) o que si bien se realice un acto con apego al debido proceso, este podría violentar un derecho fundamental (pago de pensión alimenticia, medida en que no hay una audiencia). Por lo que este trabajo examinará sobre la excepción en materia de debido proceso, para que la autoridad proteja los derechos de la contraparte. Pero queda un espacio para plantearse; si no se realiza el debido proceso, se violenta el derecho (adjetivo o sustantivo) qué tan válido será ese proceso, que pretende administrar justicia. Como se mencionó en el caso mexicano, se consideró este escenario y lo nombro: actos de molestia. Estos son reconocidos por la jurisdicción como aquellos episodios o sucesos que afectan la esfera jurídica del gobernado, que sean benéficos o favorecedores al sistema de justicia y, por tanto, a la sociedad (1). Por ejemplo, una revisión corporal, atentaría contra las normas constitucionales que nadie puede ser molestado en su persona sin una orden escrita de un juez que funde y motive, ese acto de autoridad. Sin embargo, la norma penal y las interpretaciones judiciales han considerado que, si bien se reconoce un acto de molestia, no menos cierto, es que es parte de una investigación y que también es

(1) Recuperado de https://archivos.juridicas.unam.mx/www/bjv/libros/8/3568/13.pdf [Fecha de consulta: 21/12/2018]. 
una medida que brinda seguridad al resto de la población, además de tratarse de un asunto de interés público(2).

El tribunal constitucional mexicano ha determinado que nadie puede ser molestado en su persona, familia, domicilio, papeles o posesiones, sino en virtud de mandamiento escrito de la autoridad competente, que funde y motive la causa legal del procedimiento. Los actos de molestia que, pese a constituir afectación a la esfera jurídica del gobernado, pues sólo restringen de manera provisional o preventiva un derecho con el objeto de proteger determinados bienes jurídicos; los autoriza, siempre y cuando preceda mandamiento escrito girado por una autoridad con competencia legal para ello, en donde ésta funde y motive la causa legal del procedimiento. Ahora bien, para conocer si es un acto de molestia y, por ello, es suficiente el cumplimiento de los requisitos que de ellos se exige. La finalidad es la finalidad connatural perseguida por el acto de autoridad, o bien, si por su propia índole tiende sólo a una restricción provisional(3).

\section{Bibliografía}

Bayón, J. C. (1996). Sobre la racionalidad de dictar y seguir reglas. Revista Doxa. España: Volumen.

Bix, B. (2004). Jurisprudence. USA: Carolina Academic Press.

Cabo de la Vega, A. (1997). Lo público como supuesto constitucional. México: Editorial UNAM.

Comanducci, P. (1999). Razonamiento jurídico. México: Editorial Fontamara.

Dworkin, R. (1995). Los derechos en serio. Barcelona: Editorial Ariel.

Escuin Palop, C. (2004). Curso de derecho administrativo. Valencia: Editorial Tirant lo Blanch.

Figueroa, E. (2012). Jueces y argumentación. Revista del Poder Judicial. Año (6). Perú: Volumen.

Gordillo, A. (2000). Introducción al derecho. Argentina: Editorial Fundación de Derecho Administrativo.

(2) Amparo 10/2014. Suprema Corte de Justicia de la Nación.

(3) Actos privativos y actos de molestia. Origen y efectos de la distinción. Suprema Corte de Justicia de la Nación. 
Guarnieri, C. y Pederzoli, P. (1999). Los jueces y la politica. España: Editorial Taurus.

Hamilton, A.; Madison, J. y Jay, J. (2006). El Federalista. México: Editorial FCE.

Hart,H.L.A.(1989).ElConceptodelderecho.Argentina:Editorial Abeledo-Perrot.

Herrendorf, D. E. (1994). El Poder de los jueces. Argentina: Editorial Abeledo-Perrot.

Hernández Valle, R. (1992). Los principios constitucionales. Costa Rica: Editorial Escuela Judicial. Corte Suprema de Justicia.

Negretto, G. y Ungar, M. (1997). Independencia del poder judicial y estado de derecho en américa latina. Revista Política y Gobierno. México: Volumen.

Nino, C. S. (1996). The constitution of deliberative democracy. USA: Editorial Yale.

Orozco Henríquez, J. de J. (2013). Enciclopedia jurídica mexicana. México: Editorial Porrúa.

Pérez Portilla, K. (2005). Principio de igualdad: alcance y perspectivas. México: Editorial UNAM.

Redondo, M. C. (1999). La justificación de las decisiones judiciales. Revista Isegoria, No 21. España.

Ruiz, R. (2012). La distinción entre reglas y principios. Revista Derecho y Realidad, No 21. España.

Sobrevilla, D. (2010). El modelo jurídico de reglas, principios y procedimientos en Robert Alexy. Isonomía: Revista de Teoría y Filosofía del Derecho. México.

Squella, A. (2006). Justificar decisiones jurídicas y justificar decisiones judiciales. Revista de Derecho. Vol. (IV). Chile.

Sorokin, P. (1982). Características de las normas jurídicas. Revista Chilena de Derecho. Vol. (XIX), № 2. Chile.

Trujillo, I. (2007). Imparcialidad. México: Editorial UNAM, México.

Valadés, D. (2000). El control del poder. México: Editorial UNAM.

Tribe, L. H. (1991). On reading the constitution. USA: Editorial Harvard. 
https://doi.org/10.24215/25916386e007

Villoro Toranzo, M. (1978). La norma jurídica y sus caracteres. Revista de la Facultad de Derecho. Número (111). México.

Zagrebelsky, G. (1997). El derecho dúctil. Madrid: Editorial Trotta.

\section{Jurisprudencia}

Corte Constitucional de Colombia.

Sentencia T 572/92.

Sentencia T 496/92.

Sentencia T 476/92.

Sentencia T 445/92.

Sentencia T 248/93.

Sentencia T 049/93.

Sentencia T 584/92.

Sentencia T 383/00.

Sentencia T 140/93.

Sentencia T 187/93.

Sentencia C 475/97.

Sentencia C 496-15.

Sentencia T 1232/00.

Sentencia T 073/97.

Sentencia T 516/92.

Sentencia T 1341/01.

Sentencia T 945/01.

Sentencia T 795/98.

Sentencia T 166/00. 
Sentencia T 546/00.

Sentencia T 116/04.

Sentencia T 217/96.

Sentencia C 252/01.

Sentencia T 538/94.

Sentencia C 541/92.

Sentencia T 218/96.

Sentencia T 158/93.

Sentencia T 463/92.

Sentencia T 945/99.

Fecha de recepción: 26-03-2019

Fecha de aceptación: 13-09-2019 